\title{
Conformational Stabilization of an Engineered Binding Protein
}

Elisabet Wahlberg and Torleif Härd

\section{Supporting Information}

Table S1. Mass spectrometry of double cystein mutants of the $Z_{\text {SPA-1 }}$ affibody

\begin{tabular}{|c|c|c|c|c|}
\hline Protein & & $\begin{array}{l}\text { Expected } \\
\text { mass (Da) }\end{array}$ & $\begin{array}{l}\text { Observed } \\
\text { mass }(\mathrm{Da})^{a}\end{array}$ & $\begin{array}{l}\text { Minor species } \\
\text { mass (Da) }\end{array}$ \\
\hline \multirow[t]{2}{*}{ 1: D2C/S39C } & $(\mathrm{ox})^{b}$ & 6441.4 & 6441.0 & $6572.4(+131.4)$ \\
\hline & $(\text { red })^{c}$ & 6443.4 & 6443.3 & $6574.8(+131.4)$ \\
\hline \multirow[t]{2}{*}{ 2: F5C/P38C } & (ox) & 6399.2 & 6399.3 & $\begin{array}{l}6431.3(+32.0) \\
6530.7(+131.4)\end{array}$ \\
\hline & (red) & 6401.2 & 6401.4 & $6532.7(+131.3)$ \\
\hline 3: F5C/S39C & $\begin{array}{l}\text { (ox) } \\
\text { (red) }\end{array}$ & $\begin{array}{l}6409.3 \\
6411.3\end{array}$ & $\begin{array}{l}6409.1 \\
6411.4\end{array}$ & $\begin{array}{l}6540.4(+131.3) \\
6542.8(+131.4)\end{array}$ \\
\hline \multirow[t]{2}{*}{ 4: F5C/S41C } & (ox) & 6409.3 & 6409.3 & $\begin{array}{l}6441.4(+32.1) \\
(+131 \text { also present })\end{array}$ \\
\hline & (red) & 6411.3 & 6411.5 & $6542.8(+131.3)$ \\
\hline \multirow[t]{2}{*}{ 5: N21C/A56C } & (ox) & 6458.3 & 6458.4 & $6589.7(+131.3)$ \\
\hline & (red) & 6460.3 & 6460.5 & $6591.8(+131.3)$ \\
\hline
\end{tabular}

${ }^{a}$ Predominant species.

${ }^{b}$ As purified under air oxidation.

${ }^{c}$ After addition of $1 \mathrm{mM}$ TCEP reducing agent.

Table S2. Thermal stability of five double cystein $Z_{\text {SPA-1 }}$ mutants ${ }^{a}$

\begin{tabular}{llccc}
\hline Protein & & $\begin{array}{c}\boldsymbol{T}_{\boldsymbol{m}} \\
\left({ }^{\circ} \mathrm{C}\right)\end{array}$ & $\begin{array}{c}\Delta \boldsymbol{H}^{\circ}{ }_{\text {unfold }}\left(\boldsymbol{T}_{\boldsymbol{m}}\right) \\
\left(\mathrm{kcal} \mathrm{mol}^{-1}\right)\end{array}$ & $\begin{array}{c}\Delta \boldsymbol{C}^{\circ}{ }_{\text {P, unfold }} \\
\left(\mathrm{kcal} \mathrm{mol}^{-1} \mathrm{~K}^{-1}\right)\end{array}$ \\
\hline 1: D2C/S39C & $(\text { ox })^{b}$ & $42 \pm 2$ & $23 \pm 3$ & $0.34 \pm 0.19$ \\
& $(\text { red })^{c}$ & $34 \pm 4$ & $23 \pm 5$ & $0.40 \pm 0.30$ \\
2: F5C/P38C & $(\mathrm{ox})$ & $37 \pm 1$ & $18 \pm 2$ & $0.66 \pm 0.13$ \\
& (red) & $(<20)$ & $n . d^{d}$ & n.d. \\
3: F5C/S39C & (ox) & $52.9 \pm 0.4$ & $33.2 \pm 0.9$ & $0.71 \pm 0.15$ \\
& (red) & $31 \pm 1$ & $n . d$. & n.d. \\
4: F5C/S41C & (ox) & $52.6 \pm 0.6$ & $26.8 \pm 1.5$ & $0.62 \pm 0.14$ \\
& (red) & $43.5 \pm 0.5$ & $30 \pm 2$ & $0.86 \pm 0.24$ \\
5: N21C/A56C (ox) & $71.3 \pm 0.2$ & $32.3 \pm 0.5$ & $0.1 \pm 0.07$ \\
& (red) & $27 \pm 1$ & n.d. & n.d. \\
\hline
\end{tabular}

${ }^{a}$ From fits of thermal denaturation data in Figure 3 to Equations 1 to 3 including $\Delta \mathrm{C}_{P}{ }^{o}$ unfold $\neq 0$ as an adjustable parameter.

${ }^{b}$ As purified under air oxidation.

${ }^{c}$ After addition of $1 \mathrm{mM}$ TCEP reducing agent.

${ }^{d}$ Not determined. 


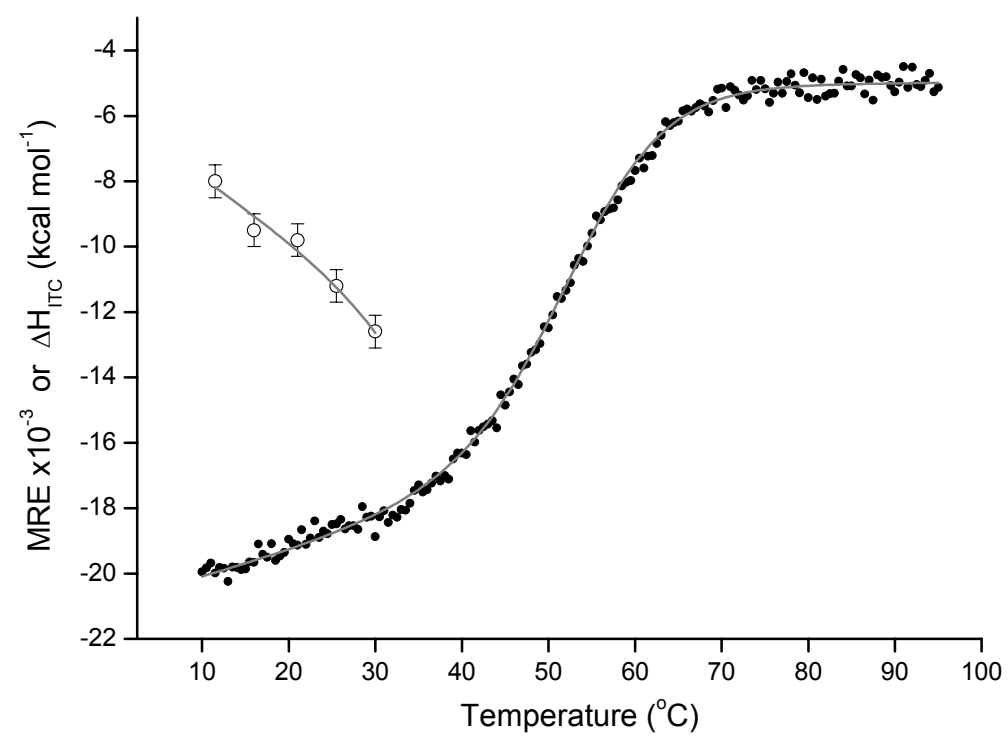

Figure S1. Global fit of thermal melting and binding of oxidized mutant 3:F5C/S39C. The MRE $(\bullet)$ of free mutant 3 and the calorimetric enthalpy for binding of mutant 3 to the $Z$ domain $\left(\Delta \mathrm{H}_{\text {ITC }} ; \circ\right)$ are shown as functions of temperature and grey lines illustrate simultaneous fitting of the two data sets to Equations 1 to 4 . The obtained thermodynamics parameters are $T_{m}=$ $52{ }^{\circ} \mathrm{C}, \Delta H_{\text {unfold }}^{o}\left(T_{m}\right)=35 \mathrm{kcal} \mathrm{mol}^{-1}, \Delta C^{\circ}{ }_{\text {P, unfold }}=0.51 \mathrm{kcal} \mathrm{mol}^{-1} \mathrm{~K}^{-1}, \Delta H^{\circ}{ }_{\text {bind }}\left(25^{\circ} \mathrm{C}\right)=-10.5 \mathrm{kcal}$ $\mathrm{mol}^{-1}$, and $\Delta C^{\circ}{ }_{P, \text { bind }}=-0.18 \mathrm{kcal} \mathrm{mol}^{-1} \mathrm{~K}^{-1}$. Errors in these values calculated from the covariance matrix are large, but the optimized values are similar to those obtained when fitting the two data sets separately, as described in the text. 